\title{
Clinical malaria diagnosis: rule-based classification statistical prototype
}

\author{
Francis Bbosa ${ }^{1}$, Ronald Wesonga ${ }^{1,2^{*}}$ and Peter Jehopio ${ }^{1}$
}

\author{
${ }^{*}$ Correspondence: \\ wesonga@wesonga.com \\ ${ }^{1}$ School of Statistics \\ and Planning, Makerere \\ University, P.O. Box 7062, \\ Kampala, Uganda \\ Full list of author information \\ is available at the end of the \\ article
}

\begin{abstract}
In this study, we identified predictors of malaria, developed data mining, statistically enhanced rule-based classification to diagnose malaria and developed an automated system to incorporate the rules and statistical models. The aim of the study was to develop a statistical prototype to perform clinical diagnosis of malaria given its adverse effects on the overall healthcare, yet its treatment remains very expensive for the majority of the patients to afford. Model validation was performed using records from two hospitals (training and predictive datasets) to evaluate system sensitivity, specificity and accuracy. The overall sensitivity of the rule-based classification obtained from the predictive dataset was $70 \%[68-74 ; 95 \% \mathrm{Cl}]$ with a specificity of $58 \%$ [54-66; $95 \% \mathrm{Cl}$. The values for both sensitivity and specificity varied by age, generally showing better performance for the data mining classification rules for the adult patients. In summary, the proposed system of data mining classification rules provides better performance for persons aged at least 18 years. However, with further modelling, this system of classification rules can provide better sensitivity, specificity and accuracy levels. In conclusion, using the system provides a preliminary test before confirmatory diagnosis is conducted in laboratories.
\end{abstract}

Keywords: Statistics, Malaria diagnosis, Rule-based classification, Sensitivity, Specificity

\section{Background}

Clinical diagnosis is the most widely applied and reliable method for drawing conclusions about the patient's malarial status (Blobel et al. 2013). It is often the only feasible approach in many circumstances, such as in rural and areas of high prevalence where patients may be willing to incur treatment costs, but are unable to pay for charges related to diagnosis (Danyliv et al. 2013; Hypponen et al. 2013; Raknes et al. 2013). This approach is inexpensive to perform and requires no specialized equipment (Epstein and Blumenfield 2001). In Uganda, a number of ongoing computer based initiatives aimed at strengthening existing health care systems at the Health facility levels have been undertaken in recent years (Wesonga et al. 2015). These initiatives include systems such as the Code 8 (Fallon 2013) and other UNICEF initiatives such as MobileVRS, DevTrac, mHealth, mTRAC, HMIS. However, all these systems are basically disease surveillance innovations and hence still lacking as far as online clinical based medical diagnosis and inference is concerned. Save for the epidemiological statistics and stocktaking, the current systems lack statistical modules such as predictive models and goodness of fit to

(c) 2016 The Author(s). This article is distributed under the terms of the Creative Commons Attribution 4.0 International License (http://creativecommons.org/licenses/by/4.0/), which permits unrestricted use, distribution, and reproduction in any medium, provided you give appropriate credit to the original author(s) and the source, provide a link to the Creative Commons license, and indicate if changes were made. 
generate necessary and timely statistics to address the knowledge gaps and challenges in the existing systems. Above all, malaria is dynamic with symptoms varying from one patient to another and can be sometimes difficult to distinguish from other diseases including typhoid and hypertension (Guwatudde et al. 2015).

Data mining brings a set of tools and techniques that can be applied to these data so as to discover hidden patterns that provide health care professionals an additional source of knowledge for making decisions (Prasanna 2011). Accordingly, (Baylis 1999; Hardin and Chhieng 2007; Hypponen et al. 2013) concur that health care is a very large domain with enormous opportunities for data mining. Data mining brings the facility to discover patterns and correlations that could be hidden within the data repository thus, the expert knowledge of the health professionals is enhanced to uncover relevant patterns; and to be more empowered since decisions rest with healthcare professionals, but not the information system experts (Baylis 1999).

According to (Epstein and Blumenfield 2001), data miners choose the data mining technique by using two main parameters; the main goal of the problem to be solved and the structure of the available data. Rule-based classifiers are explored in this study to provide a set of classification rules that can be used later to evaluate a new case and classify an already predefined set of classes for malaria. This technique is used in this study to provide a precursor to medical diagnosis of malaria using testing tools such as sensitivity and specificity of system's malarial diagnosis. Based on patients' profile, history, physical examination, diagnosis and utilizing previous treatment patterns, new treatment plans can be effectively recommended (Cunha et al. 2013; Prasanna 2011).

With the third highest number of deaths in Africa (Nankabirwa et al. 2009; Tangpukdee et al. 2009), malaria is the leading cause of morbidity in Uganda and is responsible for up to 40 percent of all outpatient visits, 25 percent of all hospital admissions and 14 percent of all hospital deaths. It was established that 95 percent of the population is at risk (Okello et al. 2006), as malaria kills between 70,000 and 100,000 children every year, a death toll that far exceeds that due to HIV/AIDS. According to many studies including (Yeka et al. 2012), malaria was an obstacle to achieving some of the most vital Millennium Development Goals (MDGs). Since 1998, Uganda has moved to adopt several key regional and international goals and targets including the overall Roll Back Malaria (RBM) Goals, the MDGs and the Africa-specific Abuja summit declaration; and all these called for the reduction of morbidity and mortality due to malaria through the scaling up of key malaria interventions to at least 60 percent of the risk populations.

Uganda attempted to meet MDG targets for the Universal Primary Education, but was not able to meet targets for the sixth goal that focused on malaria (Korenromp et al. 2013; Nankabirwa et al. 2009). The fact that Uganda failed to meet MDG 6c that is, "Have halted by 2015 and begun to reverse the incidence of malaria and other major diseases" was among the motivating factors for this study. In a 2007 resolution, the World Health Assembly called for a 75 \% reduction in malaria case incidence rates by 2015 compared to levels in the year 2000 (Kyabayinze et al. 2010). The increase in mortality and morbidity due to malaria globally and specifically in Uganda could be possibly due to high malaria diagnosis related user fees such as doctors' consultation fees, costs incurred on moving to a health facility and laboratory costs. Other challenges include; the amount of time a patient spends in queuing at the Hospital just to see a doctor, time 
spent waiting for laboratory results and duration of transit from home to hospital. In addition, other factors such as bad weather, poor road network, lack of transport means and lack of money at that time might also contribute to the increase in malaria mortality rates (Probst et al. 2007; Tediosi et al. 2008). These barriers to providing a timely diagnosis for malaria could be addressed by providing an online malarial screening system that provides the patient with information regarding his or her likely diagnosis, before he receives a confirmatory diagnosis.

In many developing countries, malaria is diagnosed via either the microscopic examination of blood films or a rapid diagnostic test (Kyabayinze et al. 2008; Piola et al. 2005). It is reported that on average, the microscopic diagnosis usually takes about $30 \mathrm{~min}$ and requires a laboratory technologist. Alternatively, a rapid diagnostic test takes on average $15 \mathrm{~min}$ to get the results can be used anywhere without a qualified Microscopist (Fallon 2013; Seidel et al. 2006). This study explored data mining techniques with statistical modules such as predictive models and goodness of fit that could generate necessary and timely statistics to address the knowledge gaps and challenges in the existing systems.

\section{Methods and data sources}

The study used malaria specific reviewed secondary data that we extracted from Form V (Patient Record Form) of the Ministry of Health from Kalisizo Hospital, a public Hospital in Rakai district in Southern Uganda and Kisubi Hospital, a private Hospital in Wakiso district in Central Uganda. The patient extraction process from Form V involved identification, recording and cleaning of the data in an Excel sheet. These data were used to develop, test and validate the malaria rules. Further, the study assessed differences in the predictors captured by public and private hospitals respectively, as well as any limitations arising from management of patients due to type of ownership of the hospital.

\section{Study population and distribution}

This study targeted persons who were 5 years and above, presenting to the hospital with malaria like symptoms. Persons below 5 years were not included due to their inability to explicitly express their symptoms to the medical worker. The variables comprised of ten signs and symptoms including; Fever, Splenomegaly, Jaundice, Joint pains, Fits, Rigors, dark urine, vomiting, febricity, drowsiness, plus malaria test outcome and the patient's age (Probst et al. 2007; Tediosi et al. 2008).

Table 1 shows the distribution of the sample and prevalence of malaria. A total of 973 records were extracted from the records showing a relatively higher prevalence of malaria (76.2 \%) in Kisubi Hospital than in Kalisizo Hospital (12.3 \%). The highest proportion of patients was those aged 18 and above (44.4\%), followed by the 5 to 9 year olds $(38.2 \%)$ and then 10 to 17 year olds (17.4\%). The difference in the malaria prevalence by hospital could be explained by susceptibilities of their locations to the anopheles mosquitoes. Whereas Kisubi Hospital is located at the shores of lake victoria, showing higher vulnerability of getting infected with malaria, Kalisizo Hospital's location is not in such an environment that exposes its inhabitants to many risks of malarial infection. The other factor could be that, whereas Kisubi Hospital serves a number of communities including; the local community, two primary schools, three secondary schools, two 
Table 1 Malaria prevalence, signs and symptoms by hospital

\begin{tabular}{llll}
\hline Malaria & $\begin{array}{l}\text { Kalisizo Hospital } \\
\text { Percentage (\%) }\end{array}$ & $\begin{array}{l}\text { Kisubi Hospital } \\
\text { Percentage (\%) }\end{array}$ & $\begin{array}{l}\text { Overall } \\
\text { Percentage (\%) }\end{array}$ \\
\hline $\begin{array}{l}\text { Proportion with malaria } \\
\text { Signs and symptoms }\end{array}$ & 12.3 & 76.2 & 22.2 \\
Febrile & & & \\
Fever & 98.2 & 53.0 & 91.2 \\
Rigors & 79.7 & 20.5 & 70.5 \\
Drowsy & 94.8 & 78.8 & 92.3 \\
Fits & 94.3 & 57.0 & 88.5 \\
Dark urine & 99.9 & 91.4 & 98.6 \\
Joint pains & 98.9 & 97.4 & 98.7 \\
Vomit & 93.2 & 90.7 & 92.8 \\
Jaundice & 96.4 & 63.6 & 91.3 \\
Splenomegaly & 100.0 & 91.4 & 98.7 \\
Total & 97.7 & 73.5 & 93.9 \\
\hline
\end{tabular}

tertiary schools and one university; Kalisizo Hospital serves only the local community around it.

Table 2 further shows malaria signs and symptoms by diagnosis. The analysis shows higher proportions of fits, dark urine, joint pains and jaundice as signs and symptoms that have strong relationships with a positive malarial outcome.

\section{Data analysis}

The classical scheme of knowledge discovery (Qin et al. 2009; Wu et al. 2008) in form of rule-based classifiers was applied to patients' records collected from two hospitals. A set of classification rules were developed, evaluated for their reliability to diagnose malaria on a new instance using a predetermined set of rules. Rule-based decision methods grouped factors providing an explicit knowledge model, which could be expressed by formal rules so as to be applied for further prediction. The technique consisted of a

Table 2 Malaria signs and symptoms by diagnosis

\begin{tabular}{llll}
\hline Signs and symptoms & \multicolumn{2}{l}{ Malaria diagnosis } \\
\cline { 2 - 4 } & Negative percentage (\%) & Positive percentage (\%) & Total percentage (\%) \\
\hline Febrile & 97.5 & 69.0 & 91.2 \\
Fever & 78.2 & 43.5 & 70.5 \\
Rigors & 94.9 & 83.3 & 92.3 \\
Drowsy & 93.7 & 70.4 & 88.5 \\
Fits & 99.7 & 94.4 & 98.6 \\
Dark urine & 98.7 & 98.6 & 98.7 \\
Joint Pains & 92.9 & 92.6 & 92.8 \\
Vomit & 95.2 & 77.3 & 91.3 \\
Jaundice & 99.7 & 94.9 & 98.7 \\
Splenomegaly & 97.5 & 81.5 & 93.9 \\
Total & 757 & 216 & 973 \\
\hline
\end{tabular}


list of rules of the form "if A and B and C, then class X", where rules for each response variable (class) were grouped together. A Positive malaria result was classified by finding the first rule whose conditions were satisfied by the case; if no rule was satisfied, the case was assigned to a default class (Zurovac et al. 2008). The process of knowledge discovery in databases (KDD) in malaria diagnosis comprised of many phases namely data cleaning, data integration, data selection, data transformation, data mining, pattern evaluation and knowledge representation (Beniwal and Arora 2012).

Before data are imported into the system, it is advisable that data processing is mandatorily carried out (Beniwal and Arora 2012) through data cleaning and multiple imputation techniques (Wesonga 2015). In this study, only $2 \%$ (about 20 values) of the data were missing on age; further consultations and review of the Form V identified 18 of the values that were missing completely at random while the remaining 2 values for age were identified from a subsidiary source with the doctor's guidance. Except for age, numeric attributes were normalized to $[0,1]$ for example, 0 for normal $\left(37^{\circ} \mathrm{C}\right)$ and 1 for temperatures higher than normal respectively. Data were then exported as comma-separated values $(\mathrm{CSV})$ into the malaria system prototype.

\section{Interpretation of the algorithm for clinical malaria diagnosis}

The study used the Information Gain (ID3) algorithm to select the attribute that minimized the value of entropy and hence maximizing the information gain. Entropy is an information-theoretic measure of the 'uncertainty' contained in a training set due to the presence of more than one possible classification (Hand et al. 2001).

Given two classes ( $\mathrm{P}$ and $\mathrm{N})$, assuming that there were $\mathrm{p}$ instances of class $\mathrm{P}$ and $\mathrm{n}$ instances of class $\mathrm{N}$, then the amount of information (in bits) that is needed to decide if an observation in the training data belonged to $\mathrm{P}$ or $\mathrm{N}$ is defined by;

$$
I(p, n)=-\left(\frac{p}{p+n}\right) \log _{2}\left(\frac{p}{p+n}\right)-\left(\frac{n}{p+n}\right) \log _{2}\left(\frac{n}{p+n}\right)
$$

Thus, assuming attribute fever, the entropy, which is the expected information needed to classify objects in all classifiers/rules is given as;

$$
E(\text { Fever })=\sum_{i=1}^{2}\left(p_{i}+n_{i}\right) /(p+n) I\left(p_{i}, n_{i}\right)
$$

The subscript $i$ refers to the number of classes for the attribute. Therefore, the encoded information gained by branching on Fever is defined as Gain (Fever $)=I(p, n)-E($ Fever $)$.

The process was repeated for each attribute by iterating through every unused attribute of the set and calculating the entropy of the attribute. The attribute with the smallest entropy (or largest information gain) value could then be selected. The set was then split by the selected attribute to produce subsets of the data. The algorithm continues to recur on each subset, considering only attributes that have not been selected before. Figure 1 shows a summary of the algorithm that generates rules for the clinical diagnosis of malaria. 
Algorithm: Generation of rules for Clinical diagnosis of malaria

Begin

Input:

Symptoms and Signs

Age category

Output: Rule/Model/Clossifier

Method:

(I) Prompt userioperator for signs and symptoms;

(2) Get signs \& symptoms;

(3) Compute Information needed to decide if obsenvation belongs to Positive (p) or Negative (n) $\quad(I(p, n))=-\left(\frac{p}{p+n}\right) \log _{2}\left(\frac{p}{p+n}\right)-\left(\frac{n}{p+n}\right) \log _{2}\left(\frac{n}{p+n}\right)$;

(4) Compute Entropy (symptom or sign) $=\Sigma_{l=1}^{2}\left(p_{l}+n_{l}\right) /(p+n) I\left(p_{l}, n_{l}\right)$ :

(5) Compute Gain(symptom or slgn $)=I(p, n)-E($ symptom or sign);

(6) Check if inputs satisfy LHS (Coverage) $=|L H S| / n$;

(7) Return classifiers that satisfy RHS in (6) above:

End.

Fig. 1 Clinical diagnosis algorithm

\section{Output evaluation}

The study applied sensitivity and specificity to evaluate the rules for the clinical malaria diagnosis algorithm. Sensitivity was computed to show the proportion of patients with malaria who tested positive while specificity represented the proportion of the patients who tested negative while applying the data mining classification rules. Other related evaluation approaches included; positive and negative predictive values for the malaria diagnosis classification rules.

Further evaluation of the classification rules for quality were assessed by following the steps outlined (Tan et al. 2002). Comparisons were done for the left-hand side, LHS and right-hand side, RHS of the rule.

- Coverage: Fraction of records that satisfied antecedent of the rule

- Coverage $=|\mathrm{LHS}| / \mathrm{n}$

- Accuracy: Fraction of records covered by the rule that belong to class on RHS

- Accuracy = |LHS n RHS|/|LHS| 
Hence, accuracy of the rule used is the fraction of instances that satisfied both the antecedent and consequent of a rule, normalized by those that satisfied the antecedent (Qin et al. 2009). It should be noted that not all inputs satisfy the condition because initially, all attributes are possible inputs in the model. However, the process is repeated recursively until we eventually end up with the significant variables that predict malaria cases by age category and thus the coverage (LHS). In other words, we only present the relevant variables in the model.

\section{Findings of the study}

To facilitate the use of the data mining classification rules, an automated system, the clinical malaria diagnosis system was developed. The problem was divided into three components: input, process and output. Outputs are the goal of the solution to the problem. Inputs are the information used to solve the problem. Processes are steps needed to convert input information into desired output results. The study also came up with a tool for collecting the above components as shown in the input process and output (IPO) diagram.

Figure 2 shows inputs, processes and outputs for the study. It can be noted that inputs included ten signs and symptoms of malaria as well as patients' age. These inputs undergoes the following processes that is, entry into the system, entropy and information gain computation for each input, rule construction/derivation, sensitivity and specificity of outputs and rule quality evaluation in order to determine the malaria outcome of any person presenting with malaria symptoms and signs.

Figure 3 shows an online-based malaria rule based interface, where the patient inputs by selecting (checking) on the user system interface all symptoms or signs being presented with; the system processes and outputs an advisory note classifying the patient as having or not having malaria. The design of the online system is based on the algorithm.

\section{Predictors of clinical malaria}

Figure 4 shows malaria outcome based on the prescribed predictors, rules and classifiers for the models of classification given the data mining rules.

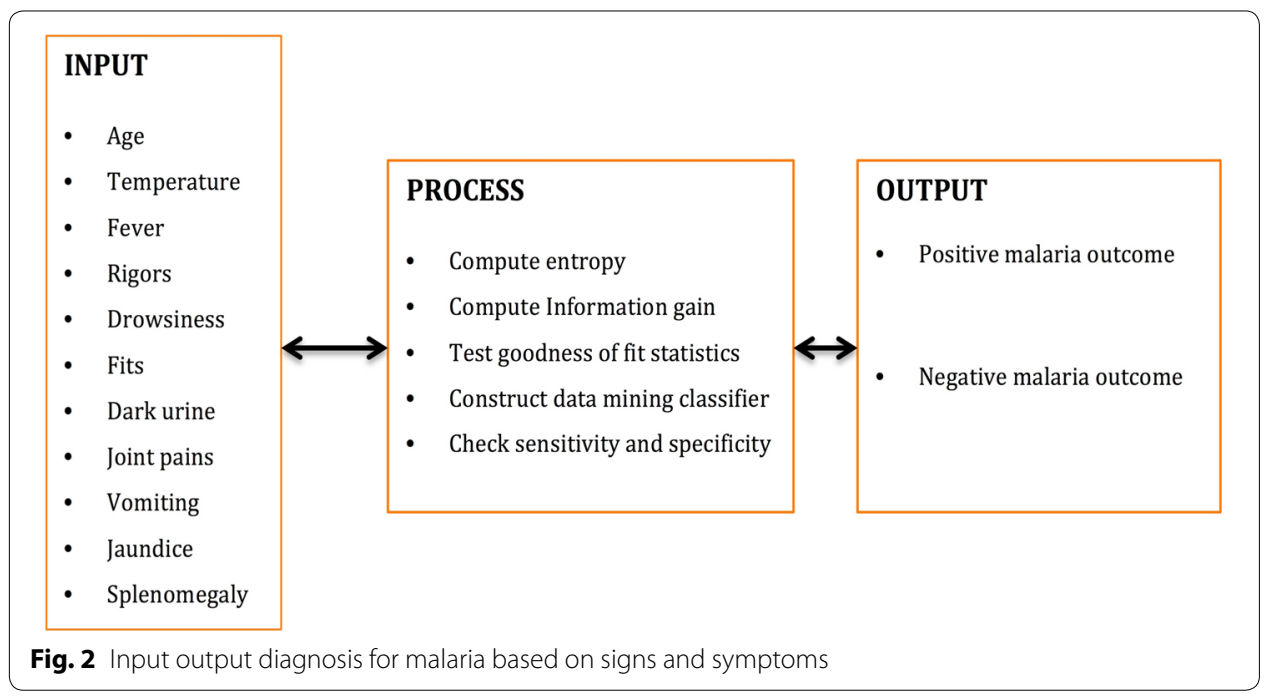




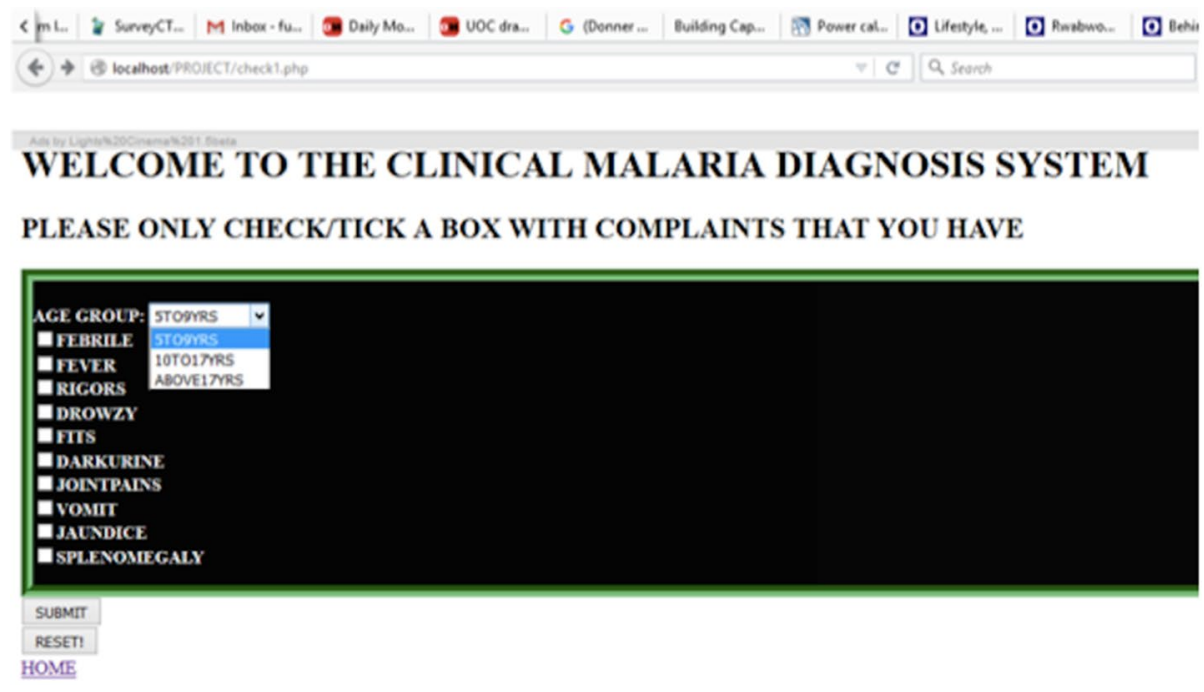

Fig. 3 Patient rule-based online interface

Table 3 illustrates data mining rule-based malaria diagnosis and classification against the symptoms and signs that a patient presents with. Rule 1 and 2 were constructed for adults, rule 3 for teenagers and rules 4, 5 and 6 for children aged from 5 to 9 years of age.

The predictors of malaria formed a logical clinical combination of the above attributes.

\section{Statistical predictive models}

The amount of Information that was gained by branching on each of the attributes is illustrated in Table 4.

Hence, the classification rules were formulated by splitting the attributes in the following descending order: Age group, Splenomegaly, Febricity, Vomit, Drowsy, Fever, Dark urine, Rigors, Joint pains respectively. Age group meant that the information gained by branching on attribute Age group is 0.028 BITs and since it had the highest information gain, the algorithm started splitting and selecting it. The above procedure was repeated for the other attributes. The overall information, I $(\mathrm{p}, \mathrm{n})$ means the amount of information needed to decide whether a patient was negative or positive given the case study was calculated as 0.538 binary digits (BITs).

\section{Goodness of fit statistics}

To test the goodness of fit of the system output, sensitivity and specificity analyses were conducted. Sensitivity refers to the proportion of patients with malaria who tested positive while specificity is the proportion of the patients who tested negative with the classification rules.

In Table 5, we present the number of patients in the predictive and training data sets. We establish the number of patients with positive and negative clinical malaria diagnosis and those determined using the classification rules. The total number of patients classified in the two hospitals was 973 of which 822 patient records were used as training data for the mining classification rules. Overall, 216 patients were positive of which 101 were from Kalisizo hospital while 115 were from Kisubi hospital. Of these, 757 patients were 


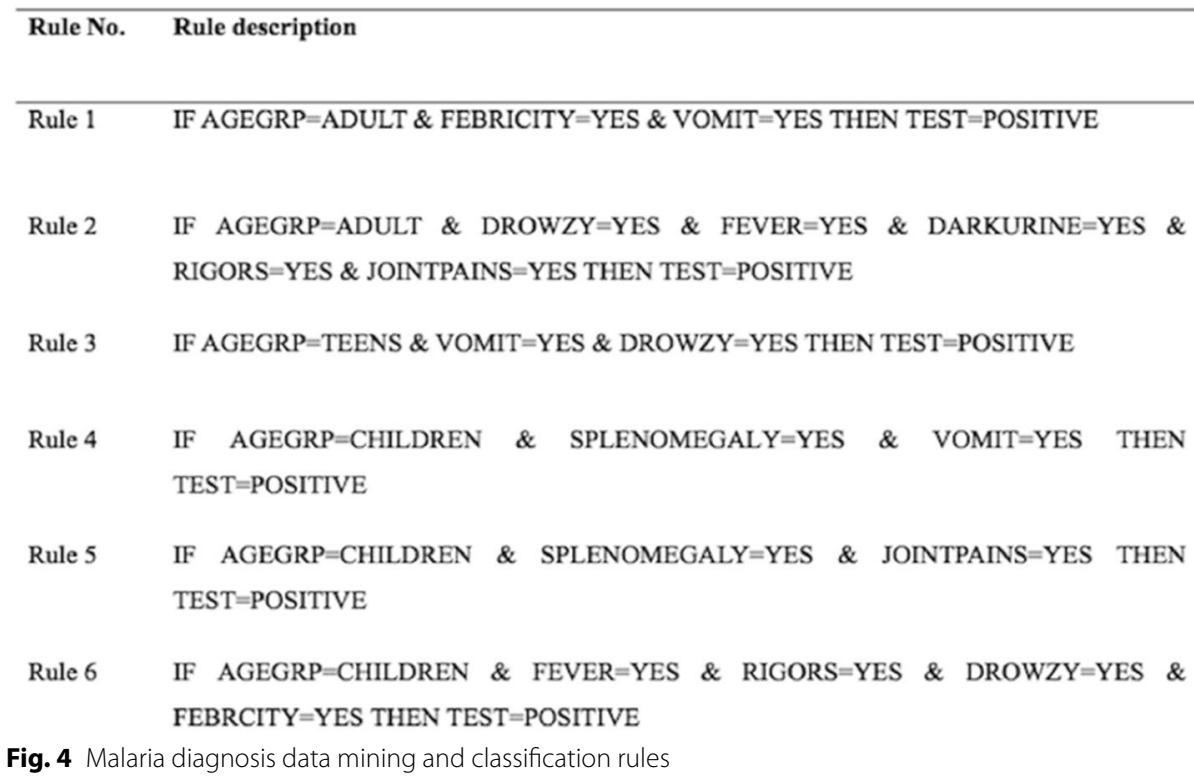

Fig. 4 Malaria diagnosis data mining and classification rules

Table 3 Malaria rule based diagnosis and classification against the symptoms and signs

\begin{tabular}{|c|c|c|c|c|c|c|}
\hline \multirow[t]{3}{*}{ Symptoms and signs } & \multicolumn{6}{|c|}{ Age category } \\
\hline & \multicolumn{2}{|c|}{$\begin{array}{l}\text { Adults } \\
\text { (18 years and above) }\end{array}$} & \multirow{2}{*}{$\begin{array}{l}\text { Teens } \\
(10-17 \text { years }) \\
\text { Rule } 3\end{array}$} & \multicolumn{3}{|c|}{$\begin{array}{l}\text { Children } \\
\text { (5-9 years) }\end{array}$} \\
\hline & Rule 1 & Rule 2 & & Rule 4 & Rule 5 & Rule 6 \\
\hline Febricity & Yes & - & - & - & - & Yes \\
\hline Drowsiness & - & Yes & Yes & - & - & Yes \\
\hline Fever & - & Yes & - & - & - & Yes \\
\hline Dark urine & - & Yes & - & - & - & - \\
\hline Rigors & - & Yes & - & - & - & Yes \\
\hline Joint pains & - & Yes & - & - & Yes & - \\
\hline Vomiting & Yes & - & Yes & Yes & - & - \\
\hline Splenomegaly & - & - & - & Yes & Yes & - \\
\hline Malaria outcome & POS & POS & POS & POS & POS & POS \\
\hline
\end{tabular}

POS positive malaria outcome

negative of which 721 were from the training dataset (Kalisizo hospital) while 36 were from the predictive dataset (Kisubi hospital).

In Table 6, we present the goodness of fit statistics by age category. Given that the rules for malaria diagnosis vary by age category, presentations for the goodness of fit statistics for different age groups and the two hospitals are made. Primarily, records from Kalisizo Hospital were used as a training dataset while records from both Kisubi Hospital were used as the predictive dataset. In data mining, the training dataset is used to develop the rules, while the predictive dataset test the sensitivity and specificity of the rule-based system. However, in our analysis, we present the goodness of fit statistics for both the predictive and training datasets. The goodness of statistics measures includes; sensitivity, specificity, positive predictive value and negative predictive values respectively. The 
Table 4 Information in binary digits gained by branching on each attribute

\begin{tabular}{ll}
\hline Symptom/sign & Information gain \\
\hline Overall I $(p, n)$ & 0.5380 \\
Age group & 0.0280 \\
Febricity & 0.0040 \\
Fever & 0.0010 \\
Rigors & 0.0005 \\
Drowzy & 0.0020 \\
Darkurine & 0.0010 \\
Joint pains & 0.0000 \\
Vomit & 0.0030 \\
Splenomegaly & 0.0130 \\
\hline
\end{tabular}

Table 5 Predicted number of patients using rule-based classification against true clinical diagnosis by age

\begin{tabular}{|c|c|c|c|c|c|c|c|c|}
\hline \multirow{3}{*}{$\begin{array}{l}\text { Predicted malarial } \\
\text { status }\end{array}$} & \multicolumn{8}{|c|}{ True clinical diagnosis of malaria } \\
\hline & \multicolumn{2}{|c|}{ 5-9 Years } & \multicolumn{2}{|c|}{$10-17$ Years } & \multicolumn{2}{|c|}{$\begin{array}{l}18 \text { Years } \\
\text { and above }\end{array}$} & \multicolumn{2}{|l|}{ Total } \\
\hline & Positive & Negative & Positive & Negative & Positive & Negative & Positive & Negative \\
\hline \multicolumn{9}{|c|}{ (a) Predictive dataset: Kalisizo Hospital } \\
\hline Positive & 6 & 4 & 10 & 3 & 65 & 8 & 81 & 15 \\
\hline Negative & 5 & 4 & 4 & 3 & 25 & 14 & 34 & 21 \\
\hline Total & 11 & 8 & 14 & 6 & 90 & 22 & 115 & 36 \\
\hline \multicolumn{9}{|c|}{ (b) Training dataset: Kisubi Hospital } \\
\hline Positive & 56 & 22 & 20 & 19 & 11 & 15 & 90 & 16 \\
\hline Negative & 5 & 270 & 5 & 105 & 4 & 290 & 11 & 705 \\
\hline Total & 61 & 292 & 25 & 124 & 15 & 305 & 101 & 721 \\
\hline
\end{tabular}

overall, sensitivity of the rule-based classification on the predictive dataset obtained from Kisubi hospital was $70 \%$ [68-74; $95 \%$ CI] with a specificity of $58 \%$ [54-66; $95 \%$ $\mathrm{CI}$. These values varied by age categories, generally showing better performance with age as shown for sensitivity analysis; 5-9 year olds $55 \%$ [43-66; $95 \%$ CI], 10-17 year olds $71 \%$ [62-80; $95 \% \mathrm{CI}$ ] and 18 and above year olds $72 \%$ [69-76; $95 \% \mathrm{CI}$ ]. Generally, the performance of the rule-based classification was found to have a better performance for the older patients than the younger ones.

The rule based classification method was used to analyse hospital data in order to identify relevant predictors of clinical malaria. In reference to the stated rules, antecedents and consequents were used to evaluate the quality of each classification rule shown in Table 7. Antecedents are the records that satisfied the left-hand side, LHS (the IF part) of the rule whereas the consequents are the records that satisfied the right-hand side, RHS (the THEN part) of the rule.

The second row of Table 6 shows the percentage composition of each age group in the predictive data. The fourth row shows the percentage of records that satisfied the antecedent of the rules. That is, for Rule (1), $17.9 \%$ of the Adults in the predictive data were covered. The fifth row shows the percentage of records covered by a rule that had 
Table 6 Goodness of fit for rule-based classification of patients' malaria outcome by age

\begin{tabular}{|c|c|c|c|c|c|c|c|c|}
\hline \multirow[t]{2}{*}{ Goodness of fit statistics } & \multicolumn{2}{|c|}{ 5-9 Years } & \multicolumn{2}{|c|}{ 10-17 Years } & \multicolumn{2}{|c|}{$\begin{array}{l}18 \text { Years } \\
\text { and above }\end{array}$} & \multicolumn{2}{|c|}{ Total } \\
\hline & $\%$ & $95 \% \mathrm{Cl}$ & $\%$ & $95 \% \mathrm{Cl}$ & $\%$ & $95 \% \mathrm{Cl}$ & $\%$ & $95 \% \mathrm{Cl}$ \\
\hline \multicolumn{9}{|c|}{ (a) Predictive dataset: Kalisizo Hospital } \\
\hline Sensitivity & 0.55 & {$[0.43-0.66]$} & 0.71 & {$[0.62-0.80]$} & 0.72 & {$[0.69-0.76]$} & 0.70 & {$[0.68-0.74]$} \\
\hline Specificity & 0.50 & {$[0.35-0.67]$} & 0.50 & {$[0.36-0.70]$} & 0.64 & {$[0.58-0.73]$} & 0.58 & {$[0.54-0.66]$} \\
\hline Positive predictive value & 0.60 & {$[0.46-0.77]$} & 0.77 & {$[0.67-0.91]$} & 0.89 & {$[0.87-0.93]$} & 0.84 & {$[0.82-0.89]$} \\
\hline Negative predictive value & 0.44 & {$[0.30-0.62]$} & 0.43 & {$[0.30-0.63]$} & 0.36 & {$[0.31-0.45]$} & 0.38 & {$[0.34-0.46]$} \\
\hline \multicolumn{9}{|c|}{ (b) Training dataset: Kisubi Hospital } \\
\hline Sensitivity & 0.92 & {$[0.90-0.93]$} & 0.80 & {$[0.74-0.83]$} & 0.73 & {$[0.63-0.76]$} & 0.89 & {$[0.87-0.90]$} \\
\hline Specificity & 0.92 & {$[0.91-0.93]$} & 0.85 & {$[0.79-0.87]$} & 0.95 & {$[0.93-0.96]$} & 0.98 & {$[0.97-0.98]$} \\
\hline Positive predictive value & 0.72 & {$[0.67-0.74]$} & 0.51 & {$[0.41-0.56]$} & 0.42 & {$[0.30-0.45]$} & 0.85 & {$[0.82-0.86]$} \\
\hline Negative predictive value & 0.98 & {$[0.98-0.98]$} & 0.95 & {$[0.94-0.96]$} & 0.99 & {$[0.98-0.99]$} & 0.98 & [0.98-0.99] \\
\hline
\end{tabular}

Table 7 Quality of the classification rule evaluation for Kisubi Hospital $(n=151)$

\begin{tabular}{lllllrl}
\hline Age group & \multicolumn{2}{l}{ Adults (18+ years) } & Teens (10-17 years) & \multicolumn{3}{l}{ Children (5-9 years) } \\
\hline Coverage by age group (\%) & 74.20 & & 13.30 & 12.50 & & \\
RULE & RULE (1) & RULE (2) & RULE (3) & RULE (4) & RULE (5) & RULE (6) \\
Coverage (\%) & 17.90 & 0.00 & 15.00 & 21.10 & 5.30 & 0.00 \\
Accuracy (\%) & 85.00 & 0.00 & 66.70 & 75.00 & 100.00 & 0.00 \\
Sample $(n)$ & 112 & & 20 & & 19 & \\
\hline
\end{tabular}

Malaria. That is, for Rule (1), when the model was compared with actual classifications in the Test data, it correctly predicted $85 \%$ cases of adults. The results in the preceding columns hold for their age groups and rules respectively.

\section{Discussion}

The prototype relied on two sources of information in order to guide exploration; approximate model using information from Training data set and a utility-model using test data which is used to refine the approximate model's predictions (Van Bever et al. 2013; Wesonga 2015). The prototype was able to achieve its intended objectives. The system contained an inbuilt database of malaria predictors as well as graphical user interfaces for the user to interact with the predictors.

The sensitivity and specificity tests of goodness of fit and entropy for the rule-based classifiers were employed by the system to test the reliability of the classification rules to diagnose malaria. The goodness of fit statistics show that overall, the data mining classification rules correctly specified $70 \%$ of patients with malaria. A similar trend was noted with specificity that showed a better performance for the adults aged 18 years and above of $72 \%$ while the lowest specificity value was $50 \%$ occurring for both categories of 5-9 and 10-17 year olds respectively. Overall, the sensitivity values for the training dataset (89 \%) were higher than those for the predictive dataset (58\%), as well as the specificity values. This is mainly because in deriving the classification rules, data from training dataset (Kalisizo hospital) were used. 
On the other hand, the entropy tests of goodness of fit show that the prototype had over $85 \%$ reliability for adult patients aged at least 18 years, which corroborates well with the sensitivity and specificity tests.

The ID3 algorithm adopted for the classification rules prototype is known to ignore irrelevant attributes and only takes into consideration attributes that are relevant to the diagnosis (malaria) problem. This implies that the user is spared the burden of getting spurious results thus improving on efficiency because the algorithm only selects attributes that minimize entropy; implying that the less one is uncertain about the results, the more the information gain and vice versa. On the other hand, there are a number of significant challenges that must be solved to enable the real-world use the prototype. These challenges include: the predictive dataset was predominantly composed of adults since this was the age group with access to Internet so as to access the system. The prototype excluded persons below the age of 5 years because they rarely explicitly express their complaints to the medical worker.

Incorporating real time feedback into the prototype was tricky since potential patients had to return to the system after the confirmatory tests were done. There was a very thin line between Malaria and Typhoid as both have some overlapping clinical features (Cunha 2007). According to (Pradhan 2011) malaria begins with multiple shaking chills, whereas typhoid fever begins with a single morning shaking chill.

\section{Conclusions}

With such statistical systems, data mining classification rules, the cost of malaria treatment, especially in developing countries, could be minimised so as to reduce, in the worst case, some otherwise avoidable mortalities due to malaria. Some system specific conclusions are drawn; firstly, the system comprised of a database of malaria predictors as well as custom driven interfaces to enable users' interact with the predictors. Secondly, the entropy, sensitivity and specificity tests for the goodness of fit were integrated as predictive models amenable to clinical diagnosis of malaria. Thirdly, rule-based classification algorithm, data mining technique, was used in the architectural design of the system to facilitate malaria diagnosis. Above all the system was tested and found to be more reliable for persons aged 18 years and above.

In summary, the study developed a prototype for predicting the patient's malarial status. The statistical prototype was evaluated for efficacy showing a sensitivity value of $70 \%$ across age groups. We are cognisant of the fact that any predictive model is not meant to replace clinical diagnosis, rather it provides screening that may require a confirmatory test. However, when appropriately used and integrated into the medical malarial investigatory system, the predictive system's malarial outcome may provide additional useful information. Lastly, although the system did not take into considerations persons below the age of 5 years, findings based on adults indicate that the system can as well be extended and adjusted for application on the children.

Authors' contributions

The authors FB and RW developed the concept; FB designed and tested the system; FB and RW drafted the manuscript. $J P, F B$ and RW reviewed the final manuscript. All authors read and approved the final manuscript.

Author details

'School of Statistics and Planning, Makerere University, P.O. Box 7062, Kampala, Uganda. ${ }^{2}$ East African Statistics Institute, P.O. Box 11140, Kampala, Uganda. 


\section{Acknowledgements}

We are thankful to the School of Statistics and Planning, Makerere University for the cordial working environment that enabled the study to be carried out successfully. We thank the staff and management Kisubi and Kalisizo hospitals. We also acknowledge the value of the comments of the two anonymous reviewers and the Editor towards shaping the manuscript.

\section{Competing interests}

The authors declare that they have no competing interests.

Received: 25 December 2015 Accepted: 20 June 2016

Published online: 30 June 2016

\section{References}

Baylis P (1999) Better health care with data mining. SPSS White Paper, UK, pp 1-8

Beniwal S, Arora J (2012) Classification and feature selection techniques in data mining. Paper presented at the International Journal of Engineering Research and Technology

Blobel B, Goossen W, Brochhausen M (2013) Clinical modeling—a critical analysis. Int J Med Inf 83(1):57-69. doi:10.1016/j. ijmedinf.2013.09.003

Cunha BA (2007) Teaching fever aphorisms: Osler revisited. Eur J Clin Microbiol Infect Dis 26(5):371-373

Cunha BA, Gran A, Munoz-Gomez S (2013) Typhoid fever vs. malaria in a febrile returning traveler: typhomalaria revisited: an Oslerian perspective. Travel Med Infect Dis 11(1):66-69

Danyliv A, Pavlova M, Gryga I, Groot W (2013) Willingness to pay for physician services at a primary contact in Ukraine: results of a contingent valuation study. BMC Health Serv Res 13(1):208

Epstein I, Blumenfield S (2001) Clinical data-mining in practice-based research: Social work in hospital settings. Routledge, London

Fallon A (Producer) (2013, August 13) Ugandan App for pain-free malaria test. http://www.ipsnews.net. Retrieved from http://www.ipsnews.net/2013/08/ugandan-app-for-pain-free-malaria-test/

Guwatudde D, Mutungi G, Wesonga R, Kajjura R, Kasule H, Muwonge J, Ssenono V, Bahendeka SK (2015) The epidemiology of hypertension in Uganda: findings from the national non-communicable diseases risk factor survey. PloS one 10(9):e0138991. doi:10.1371/journal.pone.0138991

Hand DJ, Mannila H, Smyth P (2001) Principles of data mining. MIT Press, Cambridge

Hardin JM, Chhieng DC (2007) Data mining and clinical decision support systems. In: Clinical decision support systems. Springer, New York, pp 44-63

Hypponen H, Reponen J, Laaveri T, Kaipio J (2013) User experiences with different regional health information exchange systems in Finland. Int J Med Informatics 83(1):1-18. doi:10.1016/j.jimedinf.2013.10.002

Korenromp EL, Hosseini M, Newman RD, Cibulskis RE (2013) Progress towards malaria control targets in relation to national malaria programme funding. Malar J 12:18

Kyabayinze DJ, Tibenderana JK, Odong GW, Rwakimari JB, Counihan H (2008) Operational accuracy and comparative persistent antigenicity of HRP2 rapid diagnostic tests for Plasmodium falciparum malaria in a hyperendemic region of Uganda. Malar J 7(1):221

Kyabayinze DJ, Asiimwe C, Nakanjako D, Nabakooza J, Counihan H, Tibenderana JK (2010) Research Use of RDTs to improve malaria diagnosis and fever case management at primary health care facilities in Uganda

Nankabirwa J, Zurovac D, Njogu JN, Rwakimari JB, Counihan H, Snow RW, Tibenderana JK (2009) Malaria misdiagnosis in Uganda: implications for policy change. Malar J 8:66

Okello PE, Van Bortel W, Byaruhanga AM, Correwyn A, Roelants P, Talisuna A et al (2006) Variation in malaria transmission intensity in seven sites throughout Uganda. Am J Trop Med Hyg 75(2):219-225

Piola P, Fogg C, Bajunirwe F, Biraro S, Grandesso F, Ruzagira E, Kyomuhendo J (2005) Supervised versus unsupervised intake of six-dose artemether-lumefantrine for treatment of acute, uncomplicated Plasmodium falciparum malaria in Mbarara, Uganda: a randomised trial. Lancet 365(9469):1467-1473

Pradhan P (2011) Coinfection of typhoid and malaria. J Med Lab Diag 2(3):22-26

Prasanna D (2011) Data mining for health care management. Paper presented at the 2011 SIAM international conference on data mining, Phoenix

Probst J, Laditka S, Wang J-Y, Johnson A (2007) Effects of residence and race on burden of travel for care: cross sectional analysis of the 2001 US National Household Travel Survey. BMC Health Serv Res 7(1):40

Qin B, Xia Y, Prabhakar S, Tu Y (2009) A rule-based classification algorithm for uncertain data. Paper presented at IEEE 25th international conference on the data engineering, 2009. ICDE'09

Raknes G, Hansen E, Hunskaar S (2013) Distance and utilisation of out-of-hours services in a Norwegian urban/rural district: an ecological study. BMC Health Serv Res 13(1):222

Seidel J, Beck C, Pocobelli G, Lemaire J, Bugar J, Quan H, Ghali W (2006) Location of residence associated with the likelihood of patient visit to the preoperative assessment clinic. BMC Health Serv Res 6(1):13

Tan P-N, Kumar V, Srivastava J (2002) Selecting the right interestingness measure for association patterns. Paper presented at the Proceedings of the eighth ACM SIGKDD international conference on Knowledge discovery and data mining

Tangpukdee N, Duangdee C, Wilairatana P, Krudsood S (2009) Malaria diagnosis: a brief review. Korean J Parasitol 47(2):93-102

Tediosi F, Aye R, Ibodova S, Thompson R, Wyss K (2008) Access to medicines and out of pocket payments for primary care: evidence from family medicine users in rural Tajikistan. BMC Health Serv Res 8(1):109 
Van Bever E, Wirtz VJ, Azermai M, De Loof G, Christiaens T, Nicolas L, Vander Stichele R (2013) Operational rules for the implementation of INN prescribing. Int J Med Informatics 83(1):47-56. doi:10.1016/j.jimedinf.2013.09.004

Wesonga R (2015) On multivariate imputation and forecasting of decadal wind speed missing data. SpringerPlus 4(1):1. doi:10.1186/s40064-014-0774-9

Wesonga R, Owino A, Ssekiboobo A, Atuhaire L, Jehopio P (2015) Health and human rights: a statistical measurement framework using household survey data in Uganda. BMC Int Health Hum Rights 15(1):1. doi:10.1186/ s12914-015-0049-8

Wu X, Kumar V, Quinlan JR, Ghosh J, Yang Q, Motoda H, Philip SY (2008) Top 10 algorithms in data mining. Knowl Inf Syst 14(1):1-37

Yeka A, Gasasira A, Mpimbaza A, Achan J, Nankabirwa J, Nsobya S, Talisuna A (2012) Malaria in Uganda: challenges to control on the long road to elimination: I. Epidemiology and current control efforts. Acta Trop 121(3):184-195

Zurovac D, Tibenderana JK, Nankabirwa J, Ssekitooleko J, Njogu JN, Rwakimari JB, Snow RW (2008) Malaria case-management under artemether-lumefantrine treatment policy in Uganda. Malar J 7(1):181

\section{Submit your manuscript to a SpringerOpen ${ }^{\odot}$} journal and benefit from:

- Convenient online submission

\section{- Rigorous peer review}

- Immediate publication on acceptance

- Open access: articles freely available online

- High visibility within the field

- Retaining the copyright to your article

Submit your next manuscript at $\boldsymbol{\nabla}$ springeropen.com 